4-2015

\title{
Five Factor Model Personality Profiles of University of North Dakota Unmanned Aircraft Systems Students
}

Zachary P. Waller

University of North Dakota, zachary.waller@und.edu

How does access to this work benefit you? Let us know!

Follow this and additional works at: https://commons.und.edu/avi-fac

Part of the Aviation Commons

\section{Recommended Citation}

Zachary P. Waller. "Five Factor Model Personality Profiles of University of North Dakota Unmanned Aircraft Systems Students" (2015). Aviation Faculty Publications. 3.

https://commons.und.edu/avi-fac/3

This Article is brought to you for free and open access by the Department of Aviation at UND Scholarly Commons. It has been accepted for inclusion in Aviation Faculty Publications by an authorized administrator of UND Scholarly Commons. For more information, please contact und.commons@library.und.edu. 
PEER-REVIEWED ARTICLE

FIVE FACTOR MODEL PERSONALITY PROFILES OF UNIVERSITY OF NORTH DAKOTA UNMANNED AIRCRAFT SYSTEMS STUDENTS

Zachary P. Waller

Aviation Researcher and Lecturer, University of North Dakota

\begin{abstract}
Efforts to quantify personality characteristics in the pilots of manned aircraft extend back for decades. For individuals interested in piloting Unmanned Aircraft, similar analysis of normative personality characteristics remains relatively unexplored. This research examined the Five Factor Model (FFM) personality profiles of individuals pursuing Unmanned Aircraft Systems (UAS) studies at the University of North Dakota (UND). Using the Big Five Inventory (BFI) general personality index, the responses of a UAS Student sample $(n=65)$ were compared to a Normative sample $(n=248)$ previously collected by Petros $(2013)$. The sample group, comprised of students with either Pre UAS Operations or UAS Operations declared as a first or second major, scored significantly lower in neuroticism $(\mathrm{N})(\mathrm{p}<0.001)$, significantly higher in openness (O) $(\mathrm{p}<0.01)$, and significantly higher in conscientiousness $(\mathrm{C})(\mathrm{p}<0.001)$ than individuals in the Normative sample. Based on these differences and previous work regarding the personality characteristics of manned aviators, one might hypothesize that relative to their manned counterparts, those students pursuing careers in UAS are similar in their neurotic, interpersonal, and achievement-oriented tendencies, but are distinguishable by their tendency toward introversion and openness to experience. Recommendations for future research encourage application of the Revised NEO Personality Inventory for assessment of facet traits within the FFM domains, and the exploration of these personality traits as they appear within individuals who have completed training for the operation of UAS platforms. The University of North Dakota (UND) offers a wide range of degree programs for manned aircraft, and since 2009 the nation's first major in Unmanned Aircraft Systems (UAS) Operations. Undergraduate students may specialize in majors of commercial aviation, flight education, Air Traffic Control (ATC), aviation management, or UAS Operations for a variety of reasons. As significant investments of time and money are asked of these students in the completion of their degrees, one wonders whether an in depth understanding of their characteristics could enable better academic and career advising for these student pilots.
\end{abstract}




\section{Statement of the Problem}

As the performance of pilots has been construed as " ... a product of skill, attitude and personality factors" (Chidester, Helmreich, Gregorich, \& Geis, 1991, p. 25), personnel specialists in both military and commercial aviation have worked to identify means to accurately measure the characteristics needed to be a well performing pilot (Carretta \& Ree, 2003). A great deal of effort has been made to quantify these characteristics in manned aircraft pilots. However, analysis of similar characteristics of individuals interested in piloting Unmanned Aircraft (UA) remains relatively unexplored.

Contemporary efforts regarding the operations of Unmanned Aircraft Systems have focused on technological advancement and improvement. Searches of the PsycINFO, and ERIC databases, indicate a lack of extant literature regarding the normative personality traits of students pursuing studies in UAS. The results of this study will provide information valuable to interpreting the Five Factor Model (FFM) scores of individuals pioneering this career field, and may stand to further research efforts assessing the relationship between personality traits and aspects of aviation such as pilot selection, training, retention, performance, and crew coordination in UA.

\section{Purpose of the Study}

The purpose of this study was to examine the FFM personality profiles of a contemporary sample of UND UAS students. Using the Big Five Inventory (BFI) general personality index, the responses of this group were measured against a normative sample collected previously (Petros, 2013). This comparison allowed for the identification of differences and similarities between the personalities of those students interested in pursuing studies in UAS and the general population. Results of this analysis offer a foundation which may enable future studies to determine whether personality characteristics affect areas such as training success, career persistence, or crew performance for UAS pilots.

\section{Five Factor Model of Personality}

Defined by Chidester et al. (1991), personality traits are "stable, deep-seated predispositions to respond in particular ways" (p. 27). Personality is also reflected in behaviors which are relatively stable over time and consistent across situations (Chidester et al., 1991). As some of the personality research below reflects, individual traits have a tendency to vary throughout adult life as a result of maturation and social factors (Conley, 1984). However, research has demonstrated that rank ordering of personality traits remains stable over spans of up to 45 years (Conley, 1984). The history of the BFI, and the widely used Revised NEO Personality Inventory (NEO PI-R), can be traced back through several models of personality, however, both begin in earnest with the identification and development of the FFM of personality.

The FFM of personality is a hierarchical organization of personality traits in terms of five basic dimensions: neuroticism $(\mathrm{N})$, extraversion $(\mathrm{E})$, openness $(\mathrm{O})$ to experience, agreeableness $(\mathrm{A})$, and conscientiousness (C) (McCrae \& John, 1992). Development of this model has its origins in lexical theory, or studies of natural language trait terms. As reviewed by McCrae and John (1992), "The lexical hypothesis holds that all important individual differences [in personality] will have been noted by speakers of a natural language at some point in [its] evolution and encoded in trait terms" (p. 186). In more simple terms, personality has been defined by such terms as friendly, high-strung, or punctual. These trait terms are the basic ways in which individuals understand themselves and others (McCrae \& John, 1992). It should therefore follow naturally, that, "A complete theory of personality must ultimately explain the phenomena to which these terms refer and the ways in which they are used in everyday life" (McCrae \& John, 1992, p. 186). Allport and Odbert (1936) abstracted some 4,500 trait terms from an English dictionary, and 
Cattell (1946) formed these into synonym clusters. Cattell (1979) then created rating scales to contrast the different groups of adjectives, and established his 16 Principal Factors model. It was out of this work that the NEO PI-R was subsequently developed by Costa and McCrae (Costa \& McCrae, 1992), and the BFI by John, Donahue, and Kentle (1991).

Some research offers there is much important variance in human behavior not accounted for by the FFM (Paunonen \& Jackson, 2000). Behavior domains such as religious, manipulative, erotic, and frugal, are lacking in lexical FFM results because they are not well represented in the natural language (Paunonen \& Jackson, 2000). Such research contests the lexical hypothesis in that the number of words describing a domain of behavior is not always indicative of its importance. However, even these critics acknowledge that the FFM represents prominent higher-order dimensions of individual difference which have been well encoded in the natural language (Paunonen \& Jackson, 2000).

As general personality inventories, the BFI and NEO PI-R focus on identifying personality traits of the FFM (Costa \& McCrae, 1992). As opposed to an aviation specific test or an inventory designed to identify pathology, these models allow for direct comparisons to the public. The NEO PI-R has been identified as the predominant measure of the FFM (Widiger \& Trull, 1997), and consists of 240 statements in a self-report personality battery. However, due to the number of statements and the cost, the shorter and open source, BFI was used for this study.

In contrast to the NEO PI-R, the BFI has only 44 statements which identify the same five factors of the FFM. Both inventories allow subjects to respond to each statement (e.g. 'I often feel helpless and want someone else to solve my problems', or 'I'm a superior person') on a five point Likert scale ranging from "strongly disagree" to "strongly agree." Each subject's scores are divided into the five basic domains of neuroticism, extraversion, openness, agreeableness, and conscientiousness. The NEO PI-R then further divides each of these factors into six facets through the use of additional facet specific statements. The neuroticism factor is divided into the facets of anxiety (N1), angry hostility (N2), depression (N3), self-consciousness (N4), impulsiveness (N5), and vulnerability (N6). The extraversion factor is divided into the facets of warmth (E1), gregariousness (E2), assertiveness (E3), activity (E4), excitement-seeking (E5), and positive emotions (E6). The openness factor is divided into the factors of fantasy (O1), aesthetics $(\mathrm{O} 2)$, feelings $(\mathrm{O} 3)$, actions $(\mathrm{O} 4)$, ideas $(\mathrm{O} 5)$, and values $(\mathrm{O} 6)$. The agreeableness factor is divided into the facets of trust (A1), straightforwardness (A2), altruism (A3), compliance (A4), modesty (A5), and tender-mindedness (A6). Finally, the conscientiousness factor is divided into the facets of competence (C1), order (C2), dutifulness (C3), achievement striving (C4), self-discipline (C5), and deliberation (C6) (Costa \& McCrae, 1992; Soto \& John, 2008).

As summarized by Grice and Katz (2007) the factors of neuroticism, extraversion, openness, agreeableness, and conscientiousness can be described simply as follows. The factor neuroticism contrasts emotional adjustment and stability with maladjustment such as a frequent depression or anxiety. High scores in this factor indicate maladjustment while low scores indicate emotional adjustment and stability. The factor extraversion contrasts aspects of sociability with a disposition towards introversion and independence. In this factor, higher scores indicate a tendency toward sociability. The openness factor contrasts aspects of imagination and curiosity with conventionality and obeying the rules. High scores in the openness factor indicate a more active imagination and intellectual curiosity. The agreeableness factor contrasts aspects of altruism and compliance with aspects of antagonism and egocentrism. In this factor, high scores indicate increased tendencies toward altruism and a willingness to assist others. Finally, the conscientiousness factor contrasts aspects commonly associated with character such as self-discipline and dependability with impulsivity and disorganization. High scores in consciousness are indicative of individuals who are purposeful, strong-willed, and determined. 
The validity of the NEO PI-R is well documented, and its well established norms have led to its application in several studies (Boyd, Patterson, \& Thompson, 2005). Briggs (1992) reviews that in the development of the NEO Personality Inventory (NEO PI), Costa and McCrae relied heavily on item and factor analysis to produce an inventory which measured the five factors as cleanly and as faithfully as possible (Briggs, 1992). In validating the NEO PI, Costa and McCrae "produced an impressive series of studies that underscore the ubiquity of the [FFM] in personality measurement" (Briggs, 1992, p. 277). The NEO PI provides a faithful representation of the FFM, along with more precisely identified facets within each factor (Briggs, 1992). Furthermore, its factor scales have proven robust across a variety of settings and have shown evidence of construct validity (Briggs, 1992). Similar reviews of the NEO PI-R reflect the findings of Briggs (1992), and relay that the NEO PI-R demonstrates consistent convergent and discriminant validity with respect to adjective checklist measures of the FFM (Widiger \& Trull, 1997).

To address the need for a short instrument measuring FFM components, John, et al. (1991) constructed the BFI. The BFI consists of 44 statements and was developed to create a brief inventory which would allow efficient and flexible assessment of the five factors when there is no need for more differentiated measurement of the facets discussed above. While the BFI scales include only eight or ten items for each factor, "...they do not sacrifice either content coverage or good psychometric properties" (John \& Srivastava, 1999, p. 115). In U.S. and Canadian samples, the alpha reliabilities (i.e. measures of internal consistency) of the BFI scales typically range from 0.75 to 0.90 and average above 0.80 . Three month test-retest reliabilities of the inventory range from 0.80 to 0.90 and average 0.85 (John \& Srivastava, 1999). While no direct comparisons will be made between the NEO PI-R and BFI scales in this study, tests have shown strong cross instrument validity correlations between the BFI and an abbreviated form of the NEO PI-R, the NEO Five Factor Inventory (NEO-FFI). Across all five factors, the convergent validity correlation between these instruments was $\mathrm{r}=0.73$ (John \& Srivastava, 1999).

\section{Aviation Related Personality Research}

Many exploratory research efforts have addressed the issue of identifying distinguishable personality profiles among pilot populations using the FFM of personality. While reviewing these efforts, it is essential to note that the tables are not the work of the present author, but have rather been adapted from their respective studies into a standardized format to ease comparisons and convenience for the reader.

\section{Regarding civilian pilots.}

While the applicable pool of research regarding civilian pilots is dwarfed by the efforts found among military branches, Schutte, Fitzgibbons, and Davis (2004) focused on identifying stable personality characteristics of commercial pilots. NEO PI-R scores of commercial pilots ( $\mathrm{n}=93)$ ( 88 male) from 14 different airlines indicated low levels of neuroticism, high levels of extraversion, average levels of openness and agreeableness, and very high levels of conscientiousness relative to the general public (Schutte, et al., 2004). This descriptive profile generally agrees with the more inferentially grounded profiles found among military aviators below. 


\section{Regarding military pilots.}

\section{United States Navy.}

Beginning the review of personality research in the military branches is the work of Campbell, Moore, Poythress, and Kennedy (2009). This study assessed whether a sample of clinically referred military aviators exhibited commonly occurring personality clusters. The NEO PI-R profiles of clinically referred United States Navy (USN) aviators and flight officers $(\mathrm{n}=956)$ were analyzed using model-based cluster analysis, and the emergent personality clusters were compared to clinical outcome. Two personality profiles emerged from the model-based cluster analysis, and significant differences $(p<0.001)$ in the factors of neuroticism, extraversion, agreeableness, and conscientiousness were noted. It was found that the first group $(\mathrm{n}=291)$ reported significantly higher scores in neuroticism and significantly lower scores in extraversion, agreeableness, and conscientiousness as compared to the second group $(n=665)$. When the clinical outcomes of each group were analyzed, it was found that significantly $(p<0.001)$ more members of Group 1 were deemed Not Aeronautically Adaptable (NAA), or not suited for flight duty, than of Group 2 (Campbell et al., 2009).

In 2010, Campbell, Ruiz, and Moore analyzed clinically referred military aviators to determine whether specific NEO PI-R facet differences were consistent with U.S. Navy guidelines concerning Aeronautical Adaptability (AA). The NEO PI-R scores of clinically evaluated USN aviators and flight officers ( $\mathrm{n}=954)$, who were determined either AA or NAA, were compared. The results, adapted into Table 1 below, indicated significant differences $(\mathrm{p}<0.001)$ between the AA and NAA groups for the neuroticism, extraversion, agreeableness, and conscientiousness factors, as well as differences $(p<0.01)$ in the openness factor. 
Table I. NEO PI-R Inferential Results between the Aeronautically Adaptable and Non-Aeronautically Adaptable Groups

\begin{tabular}{|c|c|c|c|c|c|c|}
\hline \multirow[b]{2}{*}{ Domains/Facets } & & \multicolumn{2}{|c|}{$\begin{array}{c}\text { AA } \\
(\mathrm{N}=817)\end{array}$} & \multicolumn{2}{|c|}{$\begin{array}{c}\text { NAA } \\
(\mathrm{N}=137)\end{array}$} & \multirow[b]{2}{*}{$\mathrm{F}(1,952)$} \\
\hline & & Mean & SD & Mean & SD & \\
\hline NEUROTICISM & $(\mathrm{N})$ & & & & & \\
\hline Anxiety & (N1) & 49.7 & 10.6 & 59.5 & 13.5 & $98.82 * *$ \\
\hline Angry Hostility & (N2) & 50.0 & 10.6 & 55.9 & 12.4 & $34.57 * *$ \\
\hline Depression & (N3) & 50.1 & 10.8 & 61.6 & 13.9 & $121.59 * *$ \\
\hline Self-Consciousness & (N4) & 50.0 & 10.2 & 56.9 & 11.9 & $51.56^{* *}$ \\
\hline Impulsiveness & (N5) & 50.1 & 11.0 & 55.3 & 13.5 & $24.75 * *$ \\
\hline Vulnerability & (N6) & 50.7 & 11.0 & 63.4 & 16.5 & $132.57 * *$ \\
\hline EXTRAVERSION & (E) & & & & & \\
\hline Warmth & $(\mathrm{E} 1)$ & 49.7 & 10.5 & 45.3 & 10.8 & $20.10 * *$ \\
\hline Gregariousness & (E2) & 50.0 & 10.2 & 46.3 & 11.4 & $15.12 * *$ \\
\hline Assertiveness & (E3) & 49.8 & 10.1 & 42.7 & 12.8 & $53.59 * *$ \\
\hline Activity & $(\mathrm{E} 4)$ & 49.1 & 10.3 & 45.5 & 10.9 & $14.23 * *$ \\
\hline Excitement-Seeking & (E5) & 49.9 & 9.8 & 46.8 & 10.5 & $11.12 * *$ \\
\hline Positive Emotions & (E6) & 49.4 & 10.8 & 43.4 & 12.3 & $35.04 * *$ \\
\hline OPENNESS & $(\mathrm{O})$ & & & & & \\
\hline Fantasy & $(\mathrm{O} 1)$ & 48.9 & 9.9 & 51.5 & 12.4 & $7.66^{* *}$ \\
\hline Aesthetics & $(\mathrm{O} 2)$ & 49.4 & 9.9 & 51.1 & 11.4 & 3.15 \\
\hline Feelings & (O3) & 49.5 & 9.9 & 52.0 & 11.1 & $7.31 * *$ \\
\hline Actions & $(\mathrm{O} 4)$ & 50.0 & 9.9 & 47.9 & 10.5 & $5.41 * *$ \\
\hline Ideas & (O5) & 49.6 & 10.0 & 50.3 & 11.2 & 0.64 \\
\hline Values & (O6) & 50.0 & 10.0 & 49.8 & 10.5 & 0.05 \\
\hline AGREEABLENESS & (A) & & & & & \\
\hline Trust & (A1) & 50.5 & 10.0 & 45.1 & 12.6 & $31.04 * *$ \\
\hline Straightforwardness & (A2) & 50.5 & 9.9 & 49.0 & 11.4 & 2.37 \\
\hline Altruism & (A3) & 49.9 & 10.3 & 47.1 & 10.9 & $8.62 * *$ \\
\hline Compliance & (A4) & 50.0 & 10.3 & 49.8 & 12.6 & 0.04 \\
\hline Modesty & (A5) & 50.7 & 10.3 & 54.2 & 11.2 & $13.76^{* *}$ \\
\hline Tender-Mindedness & (A6) & 50.3 & 9.9 & 52.0 & 10.0 & 3.62 \\
\hline CONSCIENTIOUSNESS & (C) & & & & & \\
\hline Competence & $(\mathrm{C} 1)$ & 49.8 & 10.2 & 41.5 & 13.6 & $70.93 * *$ \\
\hline Order & $(\mathrm{C} 2)$ & 49.7 & 10.0 & 47.0 & 12.6 & $7.60 * *$ \\
\hline Dutifulness & (C3) & 49.7 & 10.4 & 43.7 & 12.3 & $36.16^{* *}$ \\
\hline Achievement Striving & $(\mathrm{C} 4)$ & 49.3 & 10.4 & 44.0 & 12.4 & $29.56 * *$ \\
\hline Self-Discipline & (C5) & 50.0 & 10.3 & 42.4 & 13.5 & $59.31 * *$ \\
\hline Deliberation & (C6) & 49.9 & 10.2 & 46.2 & 11.7 & $14.86^{* *}$ \\
\hline
\end{tabular}

Personality research conducted within the USN has indicated support for the grouping of various personality scales into five-factor models, and furthered a recommendation that such models be central in USN prediction systems (Helton \& Street, 1993). Additionally, with respect to identifying personality profiles which may be incompatible with work in stressful occupations, individuals low in the neuroticism factor and high in the factors of extraversion, and conscientiousness appear to be better suited to aeronautical duties (Campbell et al., 2009; Campbell, Ruiz, et al., 2010). 


\section{United States Air Force.}

Research regarding populations within the United States Air Force (USAF) reach back to 1997 and the work of King, Callister, Retzlaff, and McGlohn. First, the personality traits of male USAF student pilots $(n=103)$, female USAF pilots $(n=103)$, and female college students $(n=103)$ were compared on the NEO PI-R. Then, NEO PI-R scores from 91 of the male and female USAF student pilots were compared to male and female mid-career USAF pilots ( $n=64$ and $n=48$ respectively), as well as male and female college students ( $\mathrm{n}=58$ and $\mathrm{n}=103$ respectively).

Results of the first study indicated differences $(p<0.001)$ between the NEO PI-R scores of the three groups. All three groups reported significantly different scores in the neuroticism factor, the USAF males being lowest followed by the USAF females. On the openness factor, USAF males were significantly lower than both female groups. Finally, significant differences were found between all groups on the conscientiousness factor. The USAF males scoring highest, followed by USAF females (King, et al., 1997).

Regarding career level differences between both male and female pilots, results illustrated a number of gender and career level differences between subjects (King, et al., 1997). Examining gender, results indicated that female college students scored significantly higher on agreeableness and conscientiousness than their male counterparts. Among USAF student pilots, the USAF female group scored higher on the factors of neuroticism and openness, but no significant differences were found in the extraversion, agreeableness or consciousness factors. Finally, the only difference noted between the mid-career pilots was in the agreeableness factor. Here the USAF female group scored significantly higher than their male counterparts (King, et al., 1997).

In 1999, Callister, King, Retzlaff, and Marsh worked to describe normative personality characteristics of USAF pilots based on the NEO PI-R. The focus of this study was establishing normative personality characteristics to ensure valid clinical assessment. The NEO PI-R test results of USAF student pilots $(\mathrm{n}=$ $1,301)$ were aggregated and compared to both male and female adult norms. Results revealed that as a group, the USAF student pilots' scores were at least 10\% higher than the general population norms in extraversion and openness, and at least 10\% lower in the agreeableness factor (Callister et al., 1999).

Of the male USAF students' $(\mathrm{n}=1,198)$ factor scores, extraversion was high, with agreeableness low. At the facet level, low scores were found in the vulnerability, values, trust, straightforwardness, compliance, and tender-mindedness facets, with high scores in gregariousness, assertiveness, activity, excitement-seeking, positive emotions, fantasy, feelings, actions, ideas, competence, dutifulness, and achievement striving. In the female USAF students $(\mathrm{n}=103)$, factor level differences were noted in high extraversion and openness scores, and low agreeableness (Callister et al., 1999).

Boyd et al. (2005) also examined personality within the USAF, seeking to determine whether significant psychological differences could predict which USAF student pilots are selected to become fighter pilots, bomber pilots, and airlift/tanker pilots. The study linked the NEO PI-R test results of student pilots ( $\mathrm{n}=$ $2,105)$ to the airframe they were later assigned. Results indicated that, in terms of the NEO PI-R, students assigned to fighters reported significantly higher scores in assertiveness, activity, conscientiousness, competence, and achievement seeking than those assigned to airlift/tankers. Students assigned to fighters also reported significantly lower scores in anxiety, self-consciousness, vulnerability, warmth, agreeableness, and tender-mindedness than those assigned to airlift/tankers. Finally, students assigned to bombers reported significantly higher scores in altruism, and tender-mindedness than those assigned to fighters. These results have been summarized in Tables 2 and 3 below, which were adapted from the works of Boyd et al. (2005). 
Table 2. NEO PI-R Descriptive Results of USAF Fighter, Bomber and Airlift/Tanker Groups

\begin{tabular}{|c|c|c|c|c|c|c|c|}
\hline \multirow[b]{2}{*}{ Domains/Facets } & & \multicolumn{2}{|c|}{$\begin{array}{l}\text { Fighter } \\
(\mathrm{N}=870)\end{array}$} & \multicolumn{2}{|c|}{$\begin{array}{c}\text { Bomber } \\
(N=159)\end{array}$} & \multicolumn{2}{|c|}{$\begin{array}{c}\text { Airlift/Tanker } \\
(\mathrm{N}=1076)\end{array}$} \\
\hline & & Mean & SD & Mean & SD & Mean & SD \\
\hline NEUROTICISM & $(\mathrm{N})$ & 45.81 & 9.49 & 47.16 & 9.27 & 46.76 & 9.32 \\
\hline Anxiety & (N1) & 46.34 & 9.30 & 46.69 & 8.72 & 48.15 & 9.30 \\
\hline Angry Hostility & (N2) & 48.37 & 10.40 & 47.63 & 9.72 & 48.02 & 9.72 \\
\hline Depression & (N3) & 46.32 & 7.95 & 46.18 & 7.57 & 46.65 & 7.95 \\
\hline Self-Consciousness & (N4) & 45.73 & 9.57 & 46.87 & 10.04 & 47.30 & 9.66 \\
\hline Impulsiveness & (N5) & 48.05 & 11.28 & 47.80 & 10.46 & 48.55 & 10.81 \\
\hline Vulnerability & (N6) & 41.30 & 8.52 & 42.08 & 8.49 & 43.21 & 8.42 \\
\hline EXTRAVERSION & (E) & 57.27 & 9.49 & 58.01 & 10.56 & 57.75 & 9.04 \\
\hline Warmth & (E1) & 51.12 & 9.65 & 51.04 & 10.54 & 52.39 & 9.25 \\
\hline Gregariousness & (E2) & 54.77 & 10.04 & 54.57 & 10.61 & 55.46 & 9.86 \\
\hline Assertiveness & (E3) & 59.23 & 9.06 & 58.02 & 9.63 & 57.20 & 9.03 \\
\hline Activity & (E4) & 59.59 & 8.40 & 58.78 & 9.96 & 57.12 & 8.89 \\
\hline Excitement-Seeking & (E5) & 61.73 & 8.53 & 61.51 & 7.87 & 61.23 & 8.21 \\
\hline Positive Emotions & (E6) & 55.06 & 9.61 & 54.30 & 10.31 & 55.13 & 9.84 \\
\hline OPENNESS & (O) & 50.70 & 10.93 & 50.67 & 9.32 & 51.06 & 9.90 \\
\hline Fantasy & (O1) & 52.61 & 10.99 & 52.49 & 11.01 & 52.96 & 10.28 \\
\hline Aesthetics & $(\mathrm{O} 2)$ & 48.86 & 11.09 & 48.98 & 10.22 & 49.86 & 10.52 \\
\hline Feelings & $(\mathrm{O} 3)$ & 51.92 & 11.21 & 52.49 & 9.50 & 53.17 & 11.26 \\
\hline Actions & $(\mathrm{O} 4)$ & 52.24 & 10.55 & 54.36 & 9.41 & 52.43 & 10.39 \\
\hline Ideas & (O5) & 54.85 & 10.71 & 53.86 & 10.46 & 53.85 & 10.42 \\
\hline Values & (O6) & 46.46 & 10.82 & 45.10 & 10.00 & 47.33 & 10.37 \\
\hline AGREEABLENESS & (A) & 43.45 & 11.03 & 44.94 & 11.07 & 45.33 & 10.66 \\
\hline Trust & (A1) & 50.48 & 10.15 & 49.67 & 11.08 & 50.17 & 10.47 \\
\hline Straightforwardness & (A2) & 48.64 & 10.01 & 48.53 & 10.63 & 48.13 & 10.33 \\
\hline Altruism & (A3) & 51.67 & 10.14 & 54.03 & 9.84 & 52.80 & 10.26 \\
\hline Compliance & (A4) & 46.01 & 11.80 & 46.96 & 12.02 & 47.16 & 10.93 \\
\hline Modesty & (A5) & 46.72 & 10.50 & 47.13 & 12.18 & 47.75 & 10.66 \\
\hline Tender-Mindedness & (A6) & 45.35 & 10.24 & 48.01 & 9.46 & 46.60 & 10.05 \\
\hline CONSCIENTIOUSNESS & (C) & 55.39 & 10.20 & 55.51 & 9.97 & 53.83 & 10.02 \\
\hline Competence & $(\mathrm{C} 1)$ & 56.81 & 8.86 & 54.91 & 8.68 & 55.06 & 9.04 \\
\hline Order & $(\mathrm{C} 2)$ & 50.21 & 10.46 & 51.57 & 10.68 & 50.41 & 10.87 \\
\hline Dutifulness & (C3) & 52.89 & 8.82 & 54.14 & 8.67 & 52.07 & 9.19 \\
\hline Achievement Striving & (C4) & 60.22 & 9.15 & 60.29 & 9.85 & 57.95 & 9.40 \\
\hline Self-Discipline & (C5) & 53.07 & 9.53 & 53.09 & 8.08 & 52.01 & 9.60 \\
\hline Deliberation & (C6) & 50.32 & 10.35 & 51.17 & 9.14 & 50.47 & 10.09 \\
\hline
\end{tabular}


Table 3. NEO PI-R Inferential Results between USAF Fighter, Bomber, and Airlift/Tanker Groups

\begin{tabular}{|c|c|c|c|c|c|}
\hline \multirow[b]{2}{*}{ Domains/Facets } & & \multicolumn{2}{|c|}{$\begin{array}{c}\text { Fighter } \\
\text { vs } \\
\text { Airlift Tanker }\end{array}$} & \multicolumn{2}{|c|}{$\begin{array}{l}\text { Fighter } \\
\text { vs } \\
\text { Bomber }\end{array}$} \\
\hline & & $\begin{array}{c}\text { Mean } \\
\text { Difference }\end{array}$ & $\mathrm{P}+$ & $\begin{array}{c}\text { Mean } \\
\text { Difference }\end{array}$ & $\mathrm{P}+$ \\
\hline NEUROTICISM & $(\mathrm{N})$ & 0.094 & 0.083 & 1.349 & 0.288 \\
\hline Anxiety & $(\mathrm{N} 1)$ & 1.802 & $0.000 *$ & 0.345 & 1.000 \\
\hline Angry Hostility & (N2) & 0.361 & 1.000 & 0.751 & 1.000 \\
\hline Depression & (N3) & 0.329 & 1.000 & 0.139 & 1.000 \\
\hline Self-Consciousness & (N4) & 1.569 & $0.002 *$ & 1.145 & 0.637 \\
\hline Impulsiveness & (N5) & 0.497 & 1.000 & 0.254 & 1.000 \\
\hline Vulnerability & (N6) & 1.916 & $0.000 *$ & 0.781 & 0.994 \\
\hline EXTRAVERSION & $(\mathrm{E})$ & 0.474 & 0.798 & 0.732 & 1.000 \\
\hline Warmth & (E1) & 1.269 & $0.014 *$ & 0.008 & 1.000 \\
\hline Gregariousness & (E2) & 0.688 & 0.431 & 0.201 & 1.000 \\
\hline Assertiveness & (E3) & 2.027 & $0.000^{*}$ & 1.216 & 0.478 \\
\hline Activity & $(\mathrm{E} 4)$ & 2.472 & $0.000 *$ & 0.814 & 0.992 \\
\hline Excitement-Seeking & (E5) & 0.502 & 0.601 & 0.224 & 1.000 \\
\hline Positive Emotions & (E6) & 0.007 & 1.000 & 0.769 & 1.000 \\
\hline OPENNESS & $(\mathrm{O})$ & 0.368 & 1.000 & 0.003 & 1.000 \\
\hline Fantasy & $(\mathrm{O} 1)$ & 0.351 & 1.000 & 0.117 & 1.000 \\
\hline Aesthetics & $(\mathrm{O} 2)$ & 1.006 & 0.139 & 0.126 & 1.000 \\
\hline Feelings & $(\mathrm{O} 3)$ & 1.241 & 0.055 & 0.568 & 1.000 \\
\hline Actions & $(\mathrm{O} 4)$ & 0.193 & 1.000 & 2.121 & 0.095 \\
\hline Ideas & (O5) & 1.007 & 0.128 & 0.991 & 0.965 \\
\hline Values & (O6) & 0.869 & 0.238 & 1.365 & 0.514 \\
\hline AGREEABLENESS & (A) & 1.877 & $0.000^{*}$ & 1.494 & 0.331 \\
\hline Trust & (A1) & 0.307 & 1.000 & 0.805 & 1.000 \\
\hline Straightforwardness & (A2) & 0.502 & 0.897 & 0.106 & 1.000 \\
\hline Altruism & (A3) & 1.139 & 0.054 & 2.365 & $0.044 *$ \\
\hline Compliance & (A4) & 1.157 & 0.090 & 0.956 & 1.000 \\
\hline Modesty & (A5) & 1.033 & 0.123 & 0.408 & 1.000 \\
\hline Tender-Mindedness & (A6) & 1.249 & $0.026^{*}$ & 2.660 & $0.017 *$ \\
\hline CONSCIENTIOUSNESS & (C) & 1.554 & $0.002 *$ & 0.122 & 1.000 \\
\hline Competence & $(\mathrm{C} 1)$ & 1.742 & $0.000 *$ & 1.898 & 0.078 \\
\hline Order & $(\mathrm{C} 2)$ & 0.197 & 1.000 & 1.357 & 0.549 \\
\hline Dutifulness & (C3) & 0.819 & 0.165 & 1.250 & 0.437 \\
\hline Achievement Striving & (C4) & 2.270 & $0.000^{*}$ & 0.006 & 1.000 \\
\hline Self-Discipline & (C5) & 1.057 & 0.055 & 0.002 & 1.000 \\
\hline Deliberation & (C6) & 0.146 & 1.000 & 0.847 & 1.000 \\
\hline $\begin{array}{l}+\mathrm{p} \text {-value: Bonferroni } \alpha \mathrm{a} \\
* \text { Indicates significance }\end{array}$ & $\begin{array}{l}\text { ustmen } \\
\text { the } 0.05\end{array}$ & $\begin{array}{l}\text { nt for mul } \\
5 \text { level }\end{array}$ & ple con & ons & \\
\hline
\end{tabular}

Continuing the analysis of personality differences with respect to gender, career, and platform assignment, Chappelle, Novy, Sowin, and Thompson (2010) evaluated the NEO PI-R scores of USAF female pilots, USAF male pilots, and non-pilot females in the civilian population. Data for this study was collected from female and male USAF pilots ( $n=512$ and $n=9,630$ respectively). Within the sample of female USAF pilots, 58 were classified as fighter/bomber pilots, 335 were tanker/transport pilots, 38 were classi- 
fied as reconnaissance pilots, 12 were helicopter pilots, and 69 were instructor pilots. Results revealed that the NEO PI-R personality profiles of female USAF pilots are closer to those of male USAF pilots than to non-pilot females in the civilian population. With regard to differences in personality according to aircraft assignment, no significant differences were discovered between the personality profiles of female USAF pilots operating different airframes (Chappelle, Novy, et al., 2010).

Also in 2010, Chappelle, McDonald, and King consolidated data from several Subject Matter Experts (SMEs) regarding attributes needed to successfully complete training and adapt to the operational demands of the Sensor Operator (SO) position in the MQ-1 Predator, and MQ-9 Reaper. Data for this study was collected from UAS SMEs ( $\mathrm{n}=69)$ including, 47 MQ-1 Predator and MQ-9 Reaper pilots, 16 SOs, and six mission intelligence coordinators. Within the responses of these SMEs, four domains were identified including (1) physical health, (2) cognitive ability, (3) personality traits, and (4) motivation. Within cognitive ability, SMEs perceived that SOs with high levels of the following aptitudes performed well and adapted more readily to the rigors and unique demands of UAS platforms, Cognitive Proficiency, Visual Perception, Attention, Spatial Processing, Memory, and Reasoning. It was perceived that SOs without adequate levels of these aptitudes struggled with timely skills acquisition, task management and prioritization, situational awareness, channelized attention, and general problem solving (Chappelle, McDonald et al., 2010).

With regard to personality traits, the SMEs identified the following non-cognitive capabilities and traits which they perceived affected SO duty performance and adaptation to the unique nature of UAS operations, Composure, Resilience, Self-Certainty, Conscientiousness, Success Orientated, Perseverance, Decisiveness, Humility, Cohesiveness, Assertiveness, and Adaptability (Chappelle, McDonald et al., 2010).

Finally, Barto, Chappelle, King, Ree, \& Teachout, (2011) compared NEO PI-R scores of a large USAF pilot sample to those of commercially published norms to support the use of both sets of norms in clinical evaluation. USAF pilot training candidates $(n=12,702)$ were sampled prior to their admission to Specialized Undergraduate Pilot Training (SUPT). Results indicated substantial mean differences between the pilot sample and the normative data for the neuroticism, extraversion, agreeableness, and consciousness factors. Subjects in the pilot group scored lower on neuroticism and agreeableness, and higher on extraversion, openness and consciousness (Barto et al., 2011). Of particular note was that female pilots scored much higher on extraversion and openness than their normative counterparts, which was consistent with the findings of Chappelle, Novy, et al., (2010). The significant differences between pilots and the normative population suggest that USAF pilots are a highly selected group and "that clinical evaluations might be quite different if only the normative population was used as a comparison group" (Barto et al., 2011, p. 12). Other research has indeed concluded that highly selected and trained aviators should be compared to other aviators rather than the general population (King, 1994).

Studies of personality in the USAF further solidify the concept that significant personality differences can be noted, not only between pilot populations and normative samples, but also across aircraft assignment, gender, and career. Furthermore, highly selected and trained aviators should be clinically assessed against other aviators, rather than the adult norm (King, 1994).

\section{United States Army.}

Grice and Katz (2007) examined the NEO PI-R profiles of U.S. Army student aviators awaiting Initial Entry Rotary Wing Training, and compared them to a sample of U.S. Army aviators. With the purpose of identifying personality differences and similarities between the groups, male U.S. Army student aviators $(n=196)$ and U.S. Army career pilots $(n=75)$ were compared to one another as well as normative personality scales.

Regarding the personality profiles of the male U.S. Army student aviators, it was found that this group was higher than average in the extraversion factor, average in the neuroticism, openness, and conscientiousness factors, and lower than average in the agreeableness factor as compared to the normative 
sample (Grice \& Katz, 2007). This profile, “... suggests that these student aviators, although outgoing and assertive, are more concerned with individualism and improving individual competence than maintaining social relationships that consume their time and energy" (Grice \& Katz, 2007, p. 18).

\section{Methodology}

Five Factor Model personality profiles of UND UAS students were examined using the BFI general personality index in the fall semester of 2013. Responses of this group were compared against a normative sample of college students previously collected (Petros, 2013). This comparison allowed for the identification of differences and similarities between those students interested in pursuing studies in UAS and the general population.

Carretta and Ree (2003) caution against several methodological issues associated with studies of personnel measurement and selection. Here, the issues most applicable are those of construct and statistical power. While the alpha reliabilities of the BFI scales are well established (John \& Srivastava, 1999), concern for statistical power, or the ability of their tests to detect an effect of a particular size (Field, 2009), in this area of study is well placed. The present study entertained statistical power no less than 0.8 , and significance at $\mathrm{p}<0.05$. For these values, a sample of 85 subjects should be sufficient to detect differences with a medium effect size $(\mathrm{r}=0.3)$, and a sample of 28 subjects should detect differences with a large effect size $(\mathrm{r}=0.5)$ (Cohen, 1992).

\section{Population}

The population for this study consisted of students enrolled as either Pre UAS Operations, or UAS Operations majors at UND ( $\mathrm{N}=123)$. Of this population, 42 students (41 males) are Pre UAS Operations, and 81 (75 males) have declared UAS Operations as either their first or second major. (Office of Institutional Research, 2013) Subject responses were not separated by race or gender in this study.

\section{Sample}

Of the 123 students with either Pre UAS Operations, or UAS Operations declared as a first or second major, 65 responses were gathered into the UAS Student sample for a 52.84\% response rate. The average age of respondents was 22.14, and no responses to the BFI were excluded from analysis. A second sample, collected previously (Petros, 2013), was used as a control group and consisted of BFI responses from 248 individuals. Unlike the UAS Student sample, scores for several FFM factors were excluded from analysis in this group due to incompleteness. Specifically, 237 responses were included in the Normative sample's neuroticism score, 234 were included in the extraversion factor score, 235 were included in the openness factor score, 234 were included in the agreeableness factor score, and 233 were included in the conscientiousness factor score. Given these samples, research results will carry limited generalizability beyond the University of North Dakota.

\section{Data Collection and Analysis}

This study was reviewed and approved by the University of North Dakota's Institutional Review Board on August 20th, 2013 as IRB Project IRB-201308-047. Subjects were informed of this study during short presentations to the Aviation 226 Introduction to UAS, Aviation 331 Systems of Unmanned Aircraft, Aviation 332 UAS Ground Control Systems, Aviation 333 UAS Sensor Systems, Aviation 334 UAS Communication and Telemetry Systems, and Aviation 338 UAS Operations classes. Advertisements were also posted throughout the on campus aerospace facilities targeting students enrolled as either a Pre UAS Operations, or UAS Operations major. Subjects were briefed on the purpose and nature of the study both in the classroom presentations and prior to receiving the survey.

The Big Five Inventory (BFI) was made available for completion during class visits as well as during two one hour time slots. The instrument was distributed to and collected from subjects by the author and subject responses were kept anonymous. Because no identifying information was collected, response 
independence (i.e. the submission of a single response set from each participant) must be assumed. The duration of subject participation did not extend beyond completion of the BFI, and no compensation was provided. Following collection, respondents' scores were aggregated and stored for analysis on a password protected drive, encrypted using Advanced Encryption Standard (AES) algorithms.

Using SPSS 21 statistics software, descriptive and inferential statistics were collected from the data. The means, standard deviations, minimum, maximum, range, and measures of skewness and kurtosis indices were calculated using the raw scores from each of the groups. A one-way Analysis of Variance (ANOVA) assessed potential relationships between the independent variables (sample group) and the dependent variables (BFI factor scores). Significance in all statistical tests were set at a minimum of $\mathrm{p}<0.05$, though significance above $\mathrm{p}<0.01$ and $\mathrm{p}<0.001$ were denoted when necessary.

\section{Results}

\section{Comparison of Descriptive Statistics}

As illustrated in Table 4, descriptive statistics for the UAS Student sample show mean scores of 2.24 for neuroticism, 3.35 for extraversion, 3.57 for openness, 3.94 for agreeableness, and 4.02 for conscientiousness. Standard deviations for the same sample were 0.61 for neuroticism, 0.76 for extraversion, 0.51 for openness, 0.60 for agreeableness, and 0.46 for conscientiousness.

Also included in Table 4 are z-scores for both the skewness and kurtosis of each factor's score distribution. For these measures, absolute values greater than 1.96 indicate significantly non-normal distributions at $\mathrm{p}<0.05$, scores greater than 2.58 are significantly non-normal at $\mathrm{p}<0.01$, and absolute values above 3.29 are significantly non-normal at $\mathrm{p}<0.001$ (Field, 2009). All factor score distributions for the UAS Student sample failed to differ significantly from a normal distribution in either skewness or kurtosis.

\section{Table 4, BFI Descriptive Results of UAS Student and Normative Sample Groups}

\begin{tabular}{|c|c|c|c|c|c|c|c|c|}
\hline Domains/Facets & & $\mathrm{N}$ & Mean & SD & Minimum & Maximum & Z skewness & Z kurtosis \\
\hline NEUROTICISM & $(\mathrm{N})$ & & & & & & & \\
\hline UAS Student Sample & & 65 & 2.24 & 0.61 & 1.00 & 3.63 & 0.13 & -0.79 \\
\hline Normative Sample & & 237 & 2.89 & 0.55 & 1.38 & 4.25 & -1.21 & -1.25 \\
\hline EXTRAVERSION & (E) & & & & & & & \\
\hline UAS Student Sample & & 65 & 3.35 & 0.76 & 1.88 & 4.63 & -0.88 & -1.56 \\
\hline Normative Sample & & 234 & 3.34 & 0.71 & 1.25 & 5.00 & 1.29 & -0.10 \\
\hline OPENNESS & (O) & & & & & & & \\
\hline UAS Student Sample & & 65 & 3.57 & 0.51 & 2.50 & 4.70 & -0.81 & -1.19 \\
\hline Normative Sample & & 235 & 3.36 & 0.53 & 2.10 & 4.90 & $2.42 *$ & -0.56 \\
\hline AGREEABLENESS & (A) & & & & & & & \\
\hline UAS Student Sample & & 65 & 3.94 & 0.60 & 2.44 & 5.00 & -1.39 & -0.72 \\
\hline Normative Sample & & 234 & 3.80 & 0.60 & 2.22 & 5.00 & -1.64 & -1.62 \\
\hline CONSCIENTIOUSNESS & (C) & & & & & & & \\
\hline UAS Student Sample & & 65 & 4.02 & 0.46 & 3.00 & 4.89 & 0.52 & -1.27 \\
\hline Normative Sample & & 233 & 3.65 & 0.55 & 2.33 & 5.00 & 0.19 & $-2.20 *$ \\
\hline
\end{tabular}

Descriptive statistics for the Normative sample, also illustrated in Table 4, show mean scores of 2.89 for neuroticism, 3.34 for extraversion, 3.36 for openness, 3.80 for agreeableness, and 3.65 for conscientiousness. Standard deviations for the same sample were 0.55 for neuroticism, 0.71 for extraversion, 0.53 for openness, 0.60 for agreeableness, and 0.55 for conscientiousness.

As with the UAS Student sample, z-scores were calculated for the skewness and kurtosis of factor score distributions in the Normative sample. While scores in the openness factor were significantly non-normal with respect to skew at $p<0.05$, it should be noted that large samples (e.g. 200 or more) will often give 
rise to small standard errors, resulting in significantly non-normal values from even small deviations in normality (Field, 2009). In such cases, a maximum threshold of 3.29 and visual examination of the distribution are considered better criterion (Field, 2009). Visual inspection of this distribution, as well as the significantly $(\mathrm{p}<0.05)$ non-normal kurtosis score of the conscientiousness factor, did not raise concern for non-normality in the Normative sample.

\section{Comparison of Means}

Results of the one way ANOVA comparing the scores of both groups for each factor are illustrated in Table 5. Significant differences were found in three of the FFM factors analyzed, neuroticism, openness, and conscientiousness. The UAS Student sample was found to have scored lower $(p<0.001)$ in neuroticism, higher $(\mathrm{p}<0.01)$ in openness, and higher $(\mathrm{p}<0.001)$ in conscientiousness than the Normative sample.

Table 5, BFI Inferential Results between UAS Student and Normative Sample Groups

\begin{tabular}{|c|c|c|c|c|c|c|}
\hline \multirow[b]{2}{*}{ Domains/Facets } & & \multicolumn{2}{|c|}{$\begin{array}{l}\text { UAS Student } \\
\text { Sample }\end{array}$} & \multicolumn{2}{|c|}{$\begin{array}{c}\text { Normative } \\
\text { Sample }\end{array}$} & \multirow[b]{2}{*}{$\mathrm{P}$} \\
\hline & & Mean & SD & Mean & SD & \\
\hline NEUROTICISM & $(\mathrm{N})$ & 2.24 & 0.61 & 2.89 & 0.55 & $0.000 * * *$ \\
\hline EXTRAVERSION & (E) & 3.35 & 0.76 & 3.34 & 0.71 & 0.987 \\
\hline OPENNESS & (O) & 3.57 & 0.51 & 3.36 & 0.53 & $0.004 * *$ \\
\hline AGREEABLENESS & (A) & 3.94 & 0.60 & 3.80 & 0.60 & 0.088 \\
\hline CONSCIENTIOUSNESS & (C) & 4.02 & 0.46 & 3.65 & 0.55 & $0.000 * * *$ \\
\hline \multicolumn{7}{|c|}{$\begin{array}{l}\text { * Indicates significance at the } 0.05 \text { level } \\
* * \text { Indicates significance at the } 0.01 \text { level } \\
* * * \text { Indicates significance at the } 0.001 \text { level }\end{array}$} \\
\hline
\end{tabular}

\section{Discussion}

Interpretation of personality results necessitates a familiarity with the basics of psychological testing, what aspects of personality the instrument measures, and the ability to integrate scale score information into a meaningful profile (Costa \& McCrae, 1992). The tendency to think in terms of types or categories should be avoided. For example, while it is convenient to think of introverts and extroverts, the FFM extraversion scale represents a continuous dimension and "... most individuals would be best described as 'ambiverts,' that is, showing a combination of introverted and extraverted tendencies" (Costa \& McCrae, 1992, p. 13). With these considerations in mind, there is no single cutoff point designating between individuals who have and do not have a given trait. Scoring average on a factor scale can be just as informative as scoring high or low. When cutoff points are needed for a particular application, they should be established empirically and only applied to the specific purpose for which they were intended (Costa \& McCrae, 1992).

Given this lack of strict dichotomy, it logically follows that raw FFM score responses carry limited meaning (Costa \& McCrae, 1992). Only when compared to the responses of others do scale score responses become valuable. This comparison among personality profiles is what enables meaningful relationships between groups.

\section{Personality Traits of UND UAS Students}

The personality traits and tendencies of those individuals pursuing UAS studies at the University of North Dakota are outlined according to each factor below. While primary interest is with respect to the Normative sample (Petros, 2013), these traits are also informally compared with many of the FFM scores of professional aviation groups outlined above. 


\section{Neuroticism.}

In neuroticism, the most pervasive domain of the FFM scales, the UAS Student sample scored significantly lower than individuals in the Normative sample. Recalling that this factor contrasts emotional stability against maladjustment or the tendency toward negative affects, this score indicates that students pursuing UAS studies are usually calm, even-tempered, and relaxed. They are able to face stressful situations without becoming upset or rattled, and are generally more emotionally stable than members of the Normative sample (Costa \& McCrae, 1992).

The UAS Students' relatively low score in neuroticism parallels the majority of findings for that trait among other aviators. Schutte, et al. (2004), found that $60 \%$ of the commercial pilots in their study scored low or very low in this factor. In military aviators, model-based cluster analysis discovered two personality profiles among clinically referred aviators. The group scoring significantly lower in neuroticism was found to contain significantly more members deemed Aeronautically Adaptable (Campbell et al., 2009). A second study on naval aviators found that Aeronautically Adaptable individuals scored significantly lower in every facet of neuroticism than individuals deemed Non-Aeronautically Adaptable (Campbell, Ruiz, et al., 2010). In King, et al. (1997) USAF student pilots were found to be significantly less neurotic than a sample of female college students. Again in 2010, USAF female pilots were found to be significantly less neurotic than a normative female sample (Chappelle, Novy, et al., 2010).

Overall, the personality traits of the UAS Student sample display a high degree of congruency with traits documented among other aviation students and professionals. This tendency to be calm, even-tempered, and relaxed, as well as the ability to face stress without becoming upset is also well aligned with the attributes composure and resilience identified by Chappelle, McDonald, et al. (2010) as traits affecting duty performance and adaptation to the unique nature of UAS operations.

\section{Extraversion.}

With respect to extraversion, there was a lack of significant difference between individuals of the UAS Student and Normative samples. This would indicate that members of the UAS Student sample display similar tendencies toward assertiveness, activity, and sociability as the Normative sample. As noted above, however, average scores on a factor scale can be just as informative as scoring high or low. This is especially true as this result is considered alongside extraversion scores documented among the majority of aviators reviewed above. With the exception of King, et al. (1997), most studies found their respective aviation samples exhibiting higher degrees of extraversion than their normative or Non-Aeronautically Adaptable samples (Barto et al., 2011; Callister et al., 1999; Campbell et al., 2009; Campbell, Ruiz, et al., 2010; Chappelle, Novy, et al., 2010; Grice \& Katz, 2007; Schutte, et al., 2004). The UAS Student results indicate an aviation population exhibiting the same degree of extraversion as their normative sample.

A lack of significant difference between the UAS Student and Normative samples is a noteworthy break from many of the personalities documented among other aviators, both civilian and military. Though an informal comparison in this study, this tendency to display more introverted traits may distinguish individuals interested in UAS from their manned aviation peers.

\section{Openness.}

Within the openness scale, the UAS Student sample showed significantly higher scores than the Normative sample. Indicating that, as a group, these individuals display a relatively more active imagination, aesthetic sensitivity, attentiveness to inner feelings, preference for variety, and intellectual curiosity (Costa $\&$ McCrae, 1992). Open individuals are willing to entertain novel ideas and unconventional values, and display a willingness to question authority. Openness scores are modestly associated with both educational and measured intelligence, and are especially related to aspects of intelligence which contribute to creativity. The scores of the UAS Student sample in this trait relative to the Normative sample again depart 
from the relative scores of many other aviation students and professionals. The openness trait of many aviators examined above do not differ from their respective normative or Non-Aeronautically Adaptable samples, (Campbell et al., 2009; Grice \& Katz, 2007; Schutte, et al., 2004). Interestingly, Campbell, Ruiz, et al. (2010) found scores of their Non-Aeronautically Adaptable sample to be significantly higher in openness than members of their Aeronautically Adaptable group, while several USAF studies discovered higher openness scores in USAF samples than the normative sample (Barto et al., 2011; Callister et al., 1999; Chappelle, Novy, et al., 2010; King, et al., 1997). Clearly, responses for the openness trait vary throughout the aviation industry and military branches. Explanation for this variety may be revealed within the higher resolution facet scores not examined by the BFI or this study.

The increased tendency of the UAS Student sample toward openness is perhaps not surprising given the emerging nature of the UAS industry. Students pursuing this degree program would be entering into profession teeming not only with novel concepts of aircraft and their capabilities, but also of unconventional modes of compliance with existing regulations both before and after these aircraft are integrated into the National Airspace System (NAS).

\section{Agreeableness.}

In agreeableness, the UAS Student sample did not differ significantly from members of the Normative sample. This indicates that members of the UAS Student sample share similar interpersonal tendencies with individuals of the Normative sample. Both are equally altruistic, sympathetic to others, and equally willing to assist with the belief that assistance will be offered in return (Costa \& McCrae, 1992). This similarity with the normative sample was shared in the traits of aviators (King, et al., 1997; Schutte, et al., 2004). However, Aeronautically Adaptable USN aviators were found to display higher agreeableness than their NAA counterparts (Campbell, Castaneda, \& Pulos, 2010; Campbell et al., 2009), and many USAF and US Army pilots were found to be less agreeable than their normative counterparts (Barto et al., 2011; Callister et al., 1999; Chappelle, Novy, et al., 2010; Grice \& Katz, 2007).

While responses of aviators in agreeableness, like openness scores, display a wide variance compared to normative samples, a dichotomy between civil and military operations seems to be present. Indeed, it is noted that while, "It is tempting to see the agreeable side of this domain as both socially preferable and psychologically healthier ... [it] is not a virtue on the battlefield or in the courtroom" (Costa \& McCrae, 1992, p. 15). Low degrees of agreeableness may be advantageous in single pilot military operations, while more normative degrees may be better suited for the interactions and resource management found in crewed and civil operations. The cohesiveness and humility traits identified as critical to the operational performance of MQ-1 and MQ-9 sensor operators (Chappelle, McDonald et al., 2010), lends support to the concept that higher relative scores in agreeableness may be desirable in crewed UAS environments.

\section{Conscientiousness.}

The UAS Student sample exhibited significantly higher scores in conscientiousness, indicating individuals who are purposeful, strong-willed, and determined. These characteristics, coupled with high scores in openness in particular, implicate a tendency toward higher academic and occupational achievement (Costa \& McCrae, 1992). Several of the traits found among Chappelle, McDonald, et al. (2010) critical traits for operational performance of MQ-1 and MQ-9 sensor operators, such as self-certainty, consciousness, and success orientated, seem to encourage high degrees of consciousness. Furthermore, relatively high degrees of this trait are also commonplace among other aviators (Barto et al., 2011; Campbell et al., 2009; Campbell, Ruiz, et al., 2010; King, et al., 1997; Schutte, et al., 2004). 


\section{JoURnAL UNMANNED \\ OFIAERIAL SYSTEMS}

\section{Conclusion and Future Studies}

The performance of pilots has been construed as the product of skill, attitude and personality factors (Chidester, et al., 1991), personnel specialists in both military and commercial aviation have worked for decades to identify means to accurately measure the characteristics needed to be a well performing pilot (Carretta \& Ree, 2003). Extant literature regarding the personality traits of manned pilots generally offers that individuals scoring relatively low in neuroticism and high in the factors of extraversion, and conscientiousness appear to be better suited to aeronautical duties.

The purpose of this study has been to examine these same FFM personality traits in a contemporary sample of students with either Pre UAS Operations, or UAS Operations declared as a first or second major. Using the BFI general personality index, responses of a UAS Student sample $(n=65)$ were compared to a Normative sample $(n=248)$. Results indicated that the UAS Student sample scored significantly lower in neuroticism $(\mathrm{p}<0.001)$, significantly higher in openness $(\mathrm{p}<0.01)$, and significantly higher in conscientiousness $(\mathrm{p}<0.001)$ as compared to individuals in the Normative sample. This UAS student personality profile of relatively low scores in neuroticism, and relatively high openness and conscientiousness scores is similar to the relatively low neuroticism and relatively high extraversion, and conscientiousness profile of individuals previously identified as better suited for aeronautical duties. Differences distinguishing between these generalized profiles are found in the extraversion and openness factors. Based on these differences, one might hypothesize that relative to their manned counterparts, those students pursuing careers in UAS are similar in their neurotic, interpersonal, and achievement-oriented tendencies, but are distinguishable by their tendency toward introversion and openness to experience.

Recommendations for future research include application of the NEO PI-R for assessment of facet traits within the FFM domains. Greater resolution within FFM factor scores may better illuminate commonalities and differences among traits such as the facet scores of openness, which displays mixed results when aggregated at the factor level. As highly selected and trained aviators should be clinically assessed against one another or other aviators (King, 1994), the exploration of FFM personality traits within individuals, both civil and military, who have completed training for the operation of UAS, as well as between those individuals and a contemporary sample of their manned aviation peers, is recommended.

The measurement of personality, particularly instruments measuring FFM traits, has had a small but valid place in the composition of pilot selection methods in the U.S. military. Contemporary works (Carretta, 2011) even vouch for its importance as selection methods are refined for future use. As subtle differences between the personality profiles of manned and unmanned pilots are explored and mapped, a foundation will be provided on which these personnel selection methods can be developed. Furthermore, it will allow for the assessment of relationships between personality and areas such as training success, career persistence, or crew performance within the new and exciting industry of UAS. 


\section{References}

Allport, G., \& Odbert, H. (1936). Trait names: A psycho-lexical study. Psychological Monographs 47.

Barto, E., Chappelle, W., King, R., Ree, M., \& Teachout, M. (2011). The NEO PI-R as a premorbid baseline measure. Brooks City Base: Air Force Research Laboratory.

Boyd, J., Patterson, J., \& Thompson, B. (2005). Psychological test profiles of USAF pilots before training vs. type aircraft flown. Aviation, Space, and Environmental Medicine 76 (5), 463-470.

Briggs, S. (1992). Assessing the five-factor model of personality description. Journal of Personality 60 (2), 253-293.

Callister, J., King, R., Retzlaff, P., \& Marsh, R. (1999). Revised NEO personality inventory profiles of male and female U.S. Air Force pilots. Military Medicine 164 (12), 885-890.

Campbell, J., Castaneda, M., \& Pulos, S. (2010). Meta-analysis of personality assessments as predictors of military aviation training success. The International Journal of Aviation Psychology 20 (1), 92-109.

Campbell, J., Moore, J., Poythress, N., \& Kennedy, C. (2009). Personality traits in clinically referred aviators: Two clusters related to occupational suitability. Aviation, Space, and Environmental Medicine 80 (9), 1049-1054.

Campbell, J., Ruiz, M., \& Moore, J. (2010). Five-factor model facet characteristics of non-aeronautically adaptable military aviators. Aviation, Space, and Environmental Medicine 81 (9), 864-868.

Carretta, T. (2011). Pilot canidate selection method, Still an effective predictor of US Air Force pilot training performance. Aviation Psychology and Applied Human Factors 1 (1), 3-8.

Carretta, T., \& Ree, M. (2003). Pilot selection methods. In P. Tsang, \& M. Vidulich, Human factors in transportation: Principles and practice of aviation psychology (pp. 357-396). Mahwah: Lawrence Erlbaum Associates.

Cattell, R. (1946). The description and measurment of personality. In World Book. Yonkers, NY.

Cattell, R. (1979). Personality and learning theory, Volume 1. New York: Springer-Verlag.

Chappelle, W., McDonald, K., \& King, R. (2010). Psychological attributes critical to the performance of MQ-1 Predator and MQ-9 Reaper U.S. Air Force sensor operators. Brooks City-Base: Air Force Research Laboratory.

Chappelle, W., Novy, P., Sowin, T., \& Thompson, W. (2010). NEO PI-R normative personality data that distinguish U.S. Air Force female pilots. Military Psychology 22, 158-175.

Chidester, T., Helmreich, R., Gregorich, S., \& Geis, C. (1991). Pilot personality and crew coordination: Implications for training and selection. The International Journal of Aviation Psychology 1 (1), 25-44.

Cohen, J. (1992). A power primer. Psychological Bulletin, 112 (1), 155-159.

Conley, J. (1984). Longitudinal consistency of adult personality: Self-reported psychological characteristics across 45 years. Journal of Personality and Social Psychology, 47 (6), 1325-1333.

Costa, P., \& McCrae, R. (1992). NEO PI-R professional manual. Odessa: Psychological Assessment Resources, Inc. 
Field, A. (2009). Discovering statistics using SPSS. London: Sage Publications.

Grice, R., \& Katz, L. (2007). Personality profiles of U.S. Army initial entry rotary wing students versus career aviators. Arlington: United States Army Research Institute for the Behavioral and Social Sciences.

John, O., \& Srivastava, S. (1999). The big five trait taxonomy: History, measurements, and theoretical perspectives. In Handbook of personality: theory and research (pp. 102-138).

John, O., Donahue, E., \& Kentle, R. (1991). The Big Five Inventory - Versions 4a and 54. Berkely, CA: University of California, Berkeley, Institude of Personality and Social Research.

King. (1994). Assessing aviators for personality pathology with the Millon Clinical Multiaxial Inventory (MCMI). Aviation, Space, and Environmental Medicine, 65 (3), 227-231.

King, R., Callister, J., Retzlaff, P., \& McGlohn, S. (1997). Pilot personality: Gender and career-level differences. Brooks AFB: United States Air Force Armstrong Laboratory.

McCrae, R., \& John, O. (1992). An introduction to the five-factor model and its applications. Journal of Personality $60(2), 175-215$.

Office of Institutional Research. (2013, September 24). Official Enrollment Reports. Retrieved October 21, 2013, from University of North Dakota: http://und.edu/research/institutional-research/_files/docs/ official/2013-fall.pdf

Paunonen, S., \& Jackson, D. (2000). What is beyond the big five? Plenty! Journal of Personality, 68 (5), 821-835.

Petros, T. (2013). Unpublished manuscript. Grand Forks, ND.

Schutte, P., Fitzgibbons, A., \& Davis, D. (2004). Pilot personality profile using the NEO-PI-R. Hampton: National Aeronautics and Space Administration.

Soto, C., \& John, O. (2008). Ten facet scales for the big five inventory: Convergence with NEO PI-R facets, self-peer agreement, and discriminant validity. Journal of Research in Personality 43, 84-90.

Widiger, T., \& Trull, T. (1997). Assessment of the five-factor model of personality. Journal of Personality Assessment 68 (2), 228-250. 